\title{
The Significance and Role of Aesthetic Education in Schooling
}

\author{
Olga Denac \\ Faculty of Education, University of Maribor, Maribor, Slovenia \\ Email: Olga.Denac@um.si
}

Received 26 August 2014; revised 20 September 2014; accepted 13 October 2014

Academic Editor: Dilek Acer, Ankara University, Turkey

Copyright (C) 2014 by author and Scientific Research Publishing Inc.

This work is licensed under the Creative Commons Attribution International License (CC BY).

http://creativecommons.org/licenses/by/4.0/

c) (i) Open Access

\begin{abstract}
Every child needs planned, aesthetic education in order to influence the experiencing, feeling and enjoying of beautiful things as a counterbalance to our currently rationalized world. Since the contemporary school strives for the development of professional knowledge and skills on the basis of intellectual actions, while (at the same time) neglecting other dimensions of the child's personality (emotions, feelings, etc.), it is one of the most important tasks of the education of children and young people to develop the ability to enjoy art and beauty, and in one's inner and outer life to act in accordance with a sense of proportion, harmony and beauty. The purpose of the article is to highlight the significance of aesthetic education in the development of the personality as a whole, to shed light on the aims of aesthetic education, to define the aesthetic dimension of experience and to ascertain the reasons for the neglect of aesthetic education in theory and practice.
\end{abstract}

\section{Keywords}

\section{Aesthetic Education, Aesthetic Experience, Planning of the Educational Process}

\section{Introduction}

Since antiquity, the idea of aesthetic education has been present in pedagogical theories as an essential element of the theoretical debate on the role of art and the beautiful in the shaping of the individual: Plato regarded aesthetic education as an indispensable composite part of the upbringing or education of the free man; Schiller says that it is possible to realize pedagogical goals only through aesthetic education and emphasizes the educational functions of the aesthetic in art, those which enrich man, cultivate him and develop within him a sense of genuine humanity; Herbart points out the danger of rational unilaterality in education and is of the opinion that 
harmony and balance in the child's personal integrity can be maintained through aesthetic culture; Read finds that the basic error of all educational systems and their methods lies in their focus on rational thinking, which can have a negative impact on the individual's inner harmony, since he has to be trained to be able to live in a creative and natural manner-and the latter can only be achieved through aesthetic education (Gilbert \& Kuhn, 1967).

The paradigms of scientific thought and modern technology have come to dominate the lives of individuals. Pedagogical classics have already warned us against paying too much attention to rationalism and to promoting the cognitive development of the child and young person. All of the critical periods in the past, and partly also in the present, see the escape from the dominance of rationalism in emphasizing the importance of aesthetic and artistic education; at the point when the child's or young person's development of integrity becomes unbalanced, this education is seen as the "last resort" in the reestablishment of harmony among the individual areas of the child's personality. Numerous authors of pedagogical concepts concerning aesthetic education (Read, 1945; Wojnar, 1978; Otto, 1974; Mollenhauer, 1996) also emphasize that the importance of the child's aesthetic development has been neglected for much too long in the planning, realization and evaluation of the educational process. As a means of preventing the scientism of the curriculum, Lenzen suggests an orientation toward the aesthetic. He claims that only then can we consider the educational process an artistic act and not a production process and, correspondingly, man a work of art and not a product (Lenzen, 1992).

Although the aesthetic comprises a wide range of notions and features from nature and social reality, art remains the most important means of aesthetic education expressed in terms of visual representations, movements, sounds, verbal expression, etc. Art participates not only in the development of the child's sensitivity but also in the integral development of the child's personality (cognitive, emotional, social and psychomotor), which should be separated from education in the artistic fields, which are narrowly professional in character and aimed merely toward developing artistic abilities. The concept of aesthetic education strives at familiarizing children with various forms of art, as only in this way can art become a vital part in the culture of the individual. Kroflič points out that "the value of arts ought to increase in the spirit of postmodern epistemology and value orientations because it is a key instrument that allows emphatic recognition of various value perspectives and raising existential questions” (Kroflič, 2007: p. 14). Spivak (2012) also claims that individuals can find a way out of emotional and physical isolation with the help of the humanities and literature. Artistic experience can guide the individual to become the humanistic ideal of personal perfection (Koopman, 2005).

\section{The Tasks of Aesthetic Education}

The most important aims and goals of aesthetic education can be described as the following: developing the aesthetic sense for the beautiful and a sense of proportion; developing aesthetic perception; experience, creating, evaluating and expressing the beautiful; developing a relationship toward nature and toward the beautiful in interpersonal relationships. Modern pedagogy teaches that each child should have the opportunity to develop his abilities to observe, experience, evaluate and create that which is beautiful. This can only be achieved if we offer children a healthy living environment and an active artistic education; in other words, curricula designed to include all of the above mentioned.

The following should be developed in children and young people:

1) The ability to perceive aesthetic qualities - in order for the child to be able to appreciate natural wonders, shapes, shades and pictures, they must be able to first notice them. This is why the development of the ability to notice the beautiful is the primary task of aesthetic education. Beauty can be found all around us, although it does not impose itself upon us, despite the fact that it exists objectively. Each noticing demands a particular level in the development of this ability. The child is incapable of noticing particular shapes if his/her ability to notice objects and forms is undeveloped. The aesthetic relationship begins with the noticing of aesthetic qualities. This ability to recognise does not simply include emotional recognition but also a rational one-mental capacities and particular types of knowledge. If our ability to recognise aesthetic qualities is not developed, we also cannot experience them;

2) The ability to experience aesthetic qualities - aesthetic qualities have to be experienced. This means that they induce feelings of excitement, joy and optimism. Such emotional states ennoble the individual and encourage him/her to also produce art themselves. The ability to experience aesthetically must also be developed and nurtured. The cognitive elements of the processes that we undergo during noticing must also include emotional 
tones with which we form impressions-and it is these that the aesthetic experience is built upon. "Someone in the state of aesthetic feeling and experiencing in a sense elevates natural forms above ordinary biological needs, and views them simply in terms of how much, as much and how they "emotionally influence" them, therefore, literally aesthetically. This is all about pure experiencing, feeling, "aesthesis" of colour, sound, and artistic quality that fills us with a feeling of beauty, composition and harmony" (Trstenjak, 1981: p. 454, 455). The aim of this task is, with the aid of aesthetic qualities, to enrich the emotional life of children and young people and the development of a sense for aesthetic values;

3) Creative capabilities - it is essential to allow children to participate in activities that will develop his/her creative abilities. This is not so much about creating aesthetic abilities in the sense of training artists, but instead about creativity which serves the general aesthetic culture, in the creation of aesthetic values in everyday life, in the environment, in the workplace. We are not simply born with creative abilities; they have to be developed. As Wallbaum (1996) claims, aesthetic perception is dependent on the relationship between the child and art, in which one's own production is much more important than being exposed to artworks and their interpretations, if this production is, of course, carried out according to aesthetic criteria;

4) Aesthetic judgement or evaluating aesthetic qualities-judging or evaluating aesthetic qualities demands formed evaluation criteria. In order for beauty to reveal its true value, we must be familiar with its particularities and its language. This task also serves general culture and not the professional training of art critics. Throughout the process of aesthetic education, the teacher must master various types of knowledge, abilities and evaluation criteria, which will help them to differentiate: the beautiful from the non-beautiful, the aesthetically valuable from the non-valuable and artistically valuable work from non-valuable work. In this way, the child will be able to develop the foundations for judging and evaluating the beautiful. The template is used to format your paper and style the text. All margins, column widths, line spaces, and text fonts are prescribed; please do not alter them. You may note peculiarities. For example, the head margin in this template measures proportionately more than is customary. This measurement and others are deliberate, using specifications that anticipate your paper as one part of the entire journals, and not as an independent document. Please do not revise any of the current designations.

\section{Aesthetic Dimensions of Experience}

Aesthetic experience is defined as understanding the content and forms of art and emotions, which is the most important aspect of aesthetic experience.

Reimer (1998) in his analysis of the arguments in defence of art mentions aesthetic education, which rests on the hypothesis that “...the aesthetic dimension of experience is a special area within cognition; it has to be understood and valued according to its intrinsic (inner) characteristics and taught in an appropriate (i.e. separate from science) manner" (Reimer, 1998: p. 150). Due to its specific structure as an aesthetic experience and the individual aspects it contains, art may be considered as an activity ensuring personal development; this gives art a special quality, which cannot be substituted with a scientific-technological approach to the recognition and sharing of knowledge (Kroflič, 2007).

In the broader sense the notion of aesthetics is not limited merely to art, but is also treated as a dimension of experience in any subject in the curriculum. Dewey (1934) and Reid (1986) claim that experience in music, fine arts and dancing as well as mathematics, history and other subjects include the aesthetic component. Indeed, in the narrower sense, the aesthetic is usually associated merely with the arts. Phenix (1964) claims that different types of art together constitute an independent area of aesthetic experience, a special category of comprehension which is of major significance in the development of human consciousness. Abbs (1994), too, claims that the aesthetic dimension is directly associated with experience in the arts and that it combines the perceptive, affective and cognitive levels in a unique manner. The arts represent a field of dynamic energy transferred through the processes of experiencing, perceiving and creating. Many authors, however, disagree with this theory. Best (1992) is of the opinion that there is no logical explanation to activities such as painting, playing instruments and creating prose having a common cognitive dimension, since it is impossible to treat musical processes and processes in other fields of art equally. According to Elliot (1995) unifying the field of music with other fields of art would mean the destruction of its essence. Gardner (1995), in his theory of multiple intelligences, also suggests that it is impossible to speak of intelligence as a unified characteristic of the human mind, but rather of various types of intelligence. He defines music as a separate intellectual ability, since the principle music opera- 
tions or components of musical intelligence are not directly related to the principle operations of other fields.

In theory, two opposing theses thus exist on the nature of art or aesthetic experience, respectively. The philosophical standpoint of theoreticians who claim that different art forms constitute a common generic essence can raise doubts as to the need for individual art subjects in the theory and practice of curriculum planning. On the other hand, the philosophical standpoint of theoreticians who emphasise the autonomy of individual artistic subjects ensures their autonomy of in the curriculum.

The various interpretations of the aesthetic-educational field have resulted in challenges in the resolving of these professional and philosophical problems and also contributed to the development of lesson planning in art subjects.

\section{Aesthetic Education and Planning the Educational Process}

Demands made in the field of aesthetic education emerge in the curricula only from the general goals, which are more or less realized in the course of various subjects. We all know that each subject offers opportunities for the development of aesthetic abilities. However, the question is to what extent teachers (class teachers, subject teachers of arts subjects, subject teachers of other subjects such as, for example, history, mathematics..., teachers in higher education) are aware of the importance of forming goals concerning the aesthetic dimension and if they are capable of implementing the goals of aesthetic education in the planned and implemented school curricula (Denac, 2011).

It is more and more evident that state institutions and various government documents or professional literature offer mostly theoretical starting points about the importance and role of aesthetic education, which are also taken into account by curriculum designers; however, they do not provide any concrete didactic approaches to teaching arts and cultural education.

Our pedagogical theory and practice lack such aesthetic thought. Individual types of artistic education are not determined on an aesthetic-theoretical basis; frequently, special didactics of artistic subjects draws on artistic techniques and does not include either the goals or processes of the aesthetic dimension, such as aesthetic perceiving, experiencing, creating, evaluating and developing aesthetic sensibilities (Denac, 1994, 1999). This is why there is an excess of theorising at the expense of experiencing, creating and evaluating within the educational process.

One of the reasons for the mentioned difficulties is undoubtedly the unresolved question of the relationship between pedagogy, general didactics and special didactics. As suggested by Dietrich, the relationship between pedagogy, general didactics and special didactics should be constructed in such a manner that more attention be paid not only to psychology, pedagogy and sociology, but also to aesthetics as the science of the beautiful and the artistic (Dietrich, 1996). General didactics forms general, socially necessary goals, which should also include goals of the aesthetic dimension, while it leaves the concretization of the latter to special didactics. Otto (1995) reflects on whether aesthetic education is really (only) the problem of special didactics. He himself is of the opinion that this problem should be dealt with as a general curricular problem.

It is also necessary to emphasize the relationship between the general pedagogical goals of the aesthetic dimension and the professional goals of individual subjects. It is most important to be aware of the general goals and consider them throughout the planning, realization and evaluation of the educational process. However, we should be aware of two potential dangers in the process of goal formation: if we do not deal with the general pedagogical goals of the aesthetic dimension and subject them to specific professional-subject goals, this can frequently lead to children losing interest in activities involving music, arts, movements, literature, etc. and ceasing to enjoy them; while if within the subjects we merely follow the general pedagogic goals, the individual subject can lose its autonomy, which means that it can be replaced by another subject field, e.g. children can choose among singing, drawing, dancing, etc. It is thus necessary, particularly in comprehensive schools, to link the professional goals with the general pedagogical goals of the aesthetic dimension.

\section{Conclusion}

Pedagogical theory and practice are to a large extent limited to the study of the intellectual development of the child's personality and tend to emphasize the production effect rather than the importance of his/her aesthetic development. The neglecting of the importance of aesthetic development in pedagogical theory and practice has made us aware of the need to systematically approach the planning, realization and evaluation of the goals of the 
aesthetic dimension.

Education should allow the individual the possibility of a responsible, independent and meaningfully complete existence, so that they can contribute, as a member of it, to a free and democratic community. As art in schools still enjoys a precarious position, education system reforms will also be required in the future. It is vital that the arts in education receive an equal, independent status in relation to other subject areas. Supporters of this perspective see arts education as a way of encouraging pupils to be the co-creators of the education process and not only passive recipients of knowledge from others. These give equal weight to the artistic and human experience, to those individuals who create and those who live in an environment in which such experiences are created-the artist and audience (Gadsden, 2008). As Reimer (1998) warns, the ultimate goal of aesthetic education is introducing us to art, undergoing aesthetic experience, and not just acquiring knowledge of art.

In order to develop aesthetic sensitivity, the teacher should encourage children and young people to actively notice, experience and create the beautiful in art, nature and interpersonal relationships; the teacher should also provide them with a variety of means for expression and self-realisation and direct contact with artworks of the highest quality. School should serve as a foundation for the achieving of the goals of aesthetic education within a variety of school subjects.

Appropriate guidance from teachers in schools and kindergarten and work with artists, elevates the cultural level of the individual and whole nation (Nevanen, Juvonen, \& Ruismaki, 2014). The international "European Multiple Choice Identity Project" offers the original use of a multitiude of approaches to developing youth identity, also utilising the artistic sphere as a tool to understanding oneself and reality, which can guide us to appropriate behaviour in current times (Kratsborn, 2009).

We can find many examples of good arts education practice, in particular in early education, where the programmes often highlight the aesthetic component and connect the cognitive and emotional fields of a child's personality (Welch, 2006; Schirrmacher, 2002). Reggio Emilia schools (Cadwell, 2003) and early education programmes such as the Montessori Method pay special attention to art and creative expression. Fantuzzo (2007), for example, introduced such a project in which literature, mathematics and social and emotional development are based on art. It was designed together with teachers and set in a teaching and social environment. By using experimental, quantitative and qualitative methods, the study can explain the success of a researchoriented approach and cooperation with the broader environment (Fantuzzo, Gadsden, \& McDermott, 2007). Such projects are an attempt to incorporate art into the education process on equal grounds.

In comparison with research in other fields, there exist very few studies about arts education whose results prove the advantage of including art in education. We have only a few examples of the best practice-case studies that we can use to support and plead for art and arts education. A lack of and insufficient access to relevant information about the "importance" of arts education for education is probably the main hindrance that prevents practice from being improved or aesthetic and arts education systematically included in education systems.

\section{References}

Abbs, P. (1994). The Educational Imperative. London: Falmer Press.

Best, D. (1992). Generic arts: an expedient myth. Journal of Art and Design Education, 11, 27-44. http://dx.doi.org/10.1111/j.1476-8070.1992.tb00686.x

Cadwell, L. (2003). Bringing Learning to Life: TheReggioApproach to Early Childhood Education. New York: Teachers College Press.

Denac, O. (1994). Targeted Planning of Aesthetic and Music Education in the Theory and Practice in Kindergarten and First Grade of Primary Schools. Educa, 6, 377-391.

Denac, O. (1999). The Influence of Aesthetic and Music Education on the Integral Development of a Child's Personality. Sodobnapedagogika, 4, 170-187.

Denac, O., Čagran, B., Denac, J., \& Sicherl Kafol, B. (2011). Arts and Cultural Education in Slovenian Primary Schools. The New Educational Review, 24, 121-132.

Dewey, J. (1934). Art as Experience. New York: Capricorn Books.

Dietrich, C. (1996). Musikalische Interaktion. Musik und Untericht, 38, 39-41.

Elliot, D. (1995). Music Maters: A New Philosophy of Music Education. New York: Oxford University Press.

Fantuzzo, J. F., Gadsden, V. L., \& McDermott, P. (2007). Evidence-Based Program for the Integration of Curricula. Interim Report to the National Institute for Child Health and Human Development. 
Gadsden, V. L. (2008). The Arts and Education: Knowledge Generation, Pedagogy, and the Discourse of Learning. Review of Research in Education, 32, 29-61. http://dx.doi.org/10.3102/0091732X07309691

Gardner, H. (1995). The Frames of Mind. Ljubljana: Tangram.

Gilbert, K. E., \& Kuhn, H. (1967). History of Aesthetics. Beograd: Kultura Beograd.

Koopman, C. (2005). Art as Fulfilment: On the Justification of Education in the Arts. Journal of Philosophy of Education, 39, 85-97. http://dx.doi.org/10.1111/j.0309-8249.2005.00421.x

Kratsborn, W. (2009). To-Gather: European Multiple Choice Identity Project. http://eacea.ec.europa.eu/llp/project reports/documents/ka4/2009/final reports/KA4 MP 505353 To Gather.doc.pdf

Kroflič, R. (2007). Educational Value of Aesthetic Experience. Sodobnapedagogika, 3, 12-30.

Lenzen, D. (1992). Paedagogik als Kunst? Kunst und Untericht, 159, 18-20.

Mollenhauer, K., Dietrich, C., \& Mueller, H.-R. (1996). Grundfragen Aesthetischer Bildung: Teorethische und Empirische Befunde zur aesthetischen Erfahrung von Kindern. Muenchen: Juventa.

Nevanen, S., Juvonen, A., \& Ruismaki, H. (2014). Kindergarten and School as a Learning Environment for Art. International Journal of Education through Art, 10, 7-23. http://dx.doi.org/10.1386/eta.10.1.7_1

Otto, G. (1974). Didaktik der Ästhetischen Erziehung. Braunschweig: Westermann.

Otto, G. (1995). Musiklehrer ohne Erziehungswissenschaft? Neue Musikzeitung, 5, 5-9.

Phenix, P. (1964). Realms of Meaning: A Philosophy of the Curriculum for General Education. New York: McGraw Hill.

Read, H. (1945). Education through Art. London: Faber and Faber.

Reimer, B. (1998). Volume IV: What Knowledge Is of Most Worth in the Arts? Philosophy of Education. Mayor Themes in the Analytic Tradition. In P. H. Hirst, \& P. White (Eds.), Problems of Educational Content and Practices (pp. 145-170). London, New York: Routledge.

Schirrmacher, R. (2002). Artand Creative Development for Young Children. Albany, NY: Delmar Thomson Learning. Spivak, G. C. (2012). An Aesthetic Education in the Era of Globalization. Cambridge, MA: Harvard University Press.

Trstenjak, A. (1981). Psychological Creativity. Ljubljana: Slovenskamatica.

Wallbaum, C. (1996). Ästhetische Wahrnehmung. Musik und Unterricht, 38, 37-42.

Welch, G. F. (2006). The Musical Development and Education of Young Children. In B. Spodek, \& O. N. Saracho (Eds.), Handbook of Research on the Education of Young Children (pp. 251-267). Mahwah, NJ: Lawrence Erlbaum.

Wojnar, I. (1978). Aesthetic Education. Journal of Aesthetic Education, 4, 41-54. http://dx.doi.org/10.2307/3332044 
Scientific Research Publishing (SCIRP) is one of the largest Open Access journal publishers. It is currently publishing more than 200 open access, online, peer-reviewed journals covering a wide range of academic disciplines. SCIRP serves the worldwide academic communities and contributes to the progress and application of science with its publication.

Other selected journals from SCIRP are listed as below. Submit your manuscript to us via either submit@scirp.org or Online Submission Portal.
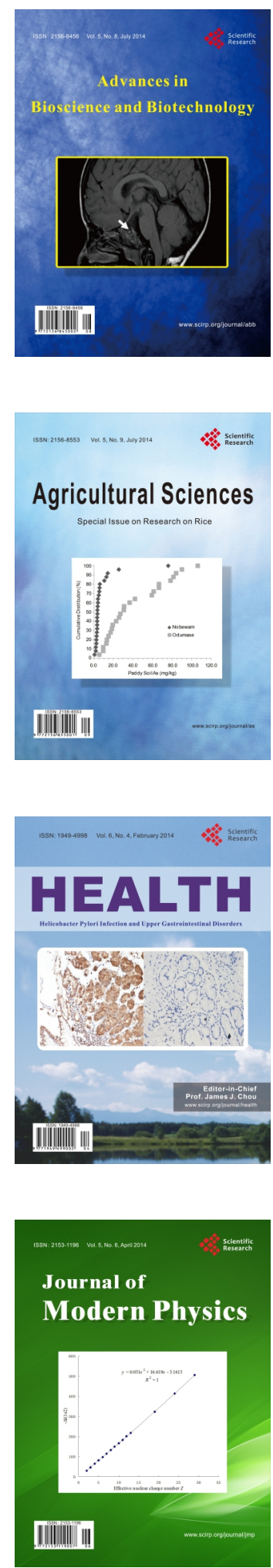
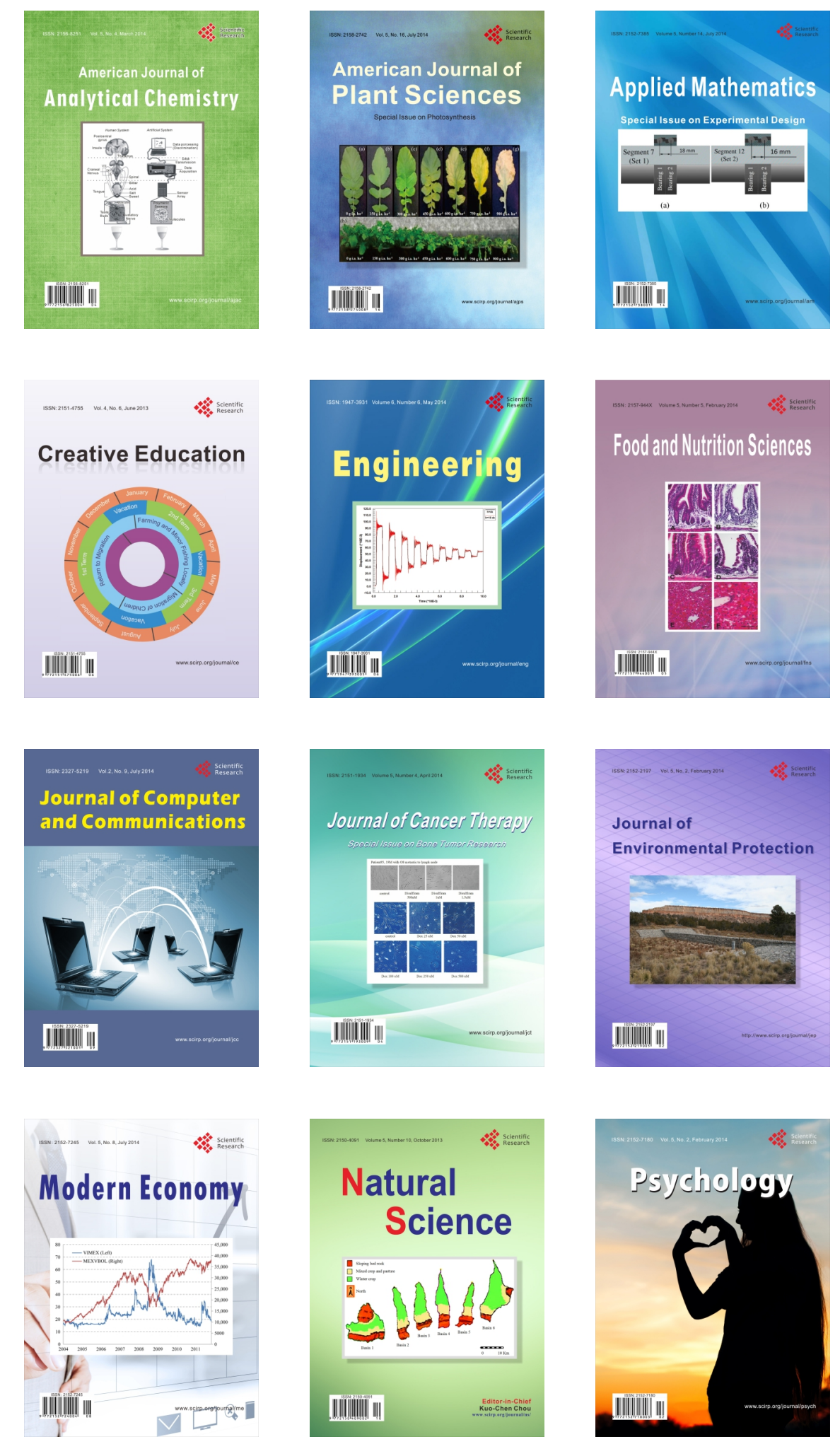